\title{
EVALUATION OF FOREST AND CLIMATE CHANGE EMPOWERMENT PROGRAMS OF LONG LAAI VILLAGE, KECAMATAN SEGAH BERAU DISTRICT
}

\section{EVALUASI PROGRAM PEMBERDAYAAN FOREST AND CLIMATE CHANGE PROGRAMME DESA LONG LAAI KECAMATAN SEGAH KABUPATEN BERAU}

\author{
Herman Anye ${ }^{1}$, Novita Suryaningsih ${ }^{2}$ \\ Universitas Mulawarman, Indonesia
}

Email Correspondence: hermananye@gmail.com

\begin{abstract}
:
The community participation program in conserving village forests is carried out by the Forest and Climate Change Program of Long Laai Village. Indonesia's forest is one of the third largest tropical forests in the world and is ranked second in terms of diversity. From an ecological, economic and social perspective, it turns out that the level of forest destruction in Indonesia is still relatively high from year to year due to uncontrolled exploitation activities carried out massively without paying attention to sustainability and sustainability. Kalimantan is one of the lungs of the world whose forest area is 40.8 million hectares. According to data released by the forestry department, the deforestation rate in Kalimantan from 2000 to 2005 reached around 1.23 million hectares. Berau District has an area of 2,194,299,525 hectares consisting of protection forest, limited production forest, permanent production forest, conservation forest and other areas of use. The successes and failures achieved by the community and the Forest and Climate Change program and the supporting and hindering factors for the program's running are a village approach strategy to raise community awareness in maintaining and utilizing forest products.
\end{abstract}

\section{Keywords: Community, Forclime, Forests, Participation}

\begin{abstract}
ABSTRAK:
Program partisipasi masyarakat dalam melestarikan hutan desa dilaksanakan oleh Forest and Climate Change Programme Desa Long Laai. Hutan Indonesia merupakan salah satu hutan tropis terluas ketiga di dunia dan ditempatkan pada urutan kedua dalam hal tingkat keanekaragaman. Dari sisi ekologi, ekonomi dan sosial ternyata tingkat kerusakkan hutan di Indonesia masih relatif tinggi dari tahun ketahun diakibatkan kegiatan eksploitasi yang tidak terkendali dan dilakukan secara masif tanpa memperhatikan kelestarian serta keberlanjutan. Kalimantan adalah salah satu paru-paru dunia luas hutannya yaitu, 40,8 juta hektar. Menurut data yang dikeluarkan departemen kehutanan angka deforestasi Kalimantan pada tahun 2000 sampai 2005 mencapai sekitar 1,23 juta hektar. Kabupaten Berau memiliki luas wilayah 2.194.299,525 Ha yang terdiri dari Hutan Lindung, Hutan Produksi Terbatas, Hutan Produksi Tetap, Hutan Konservasi, dan Areal penggunaan Lain. Keberhasilan dan kegagalan yang dicapai masyarakat dan Forest and Climate Change programme dan faktor pedukung dan penghambat jalannya program ada strategi pendekatan desa untuk membangkitkan kesadaran masyarakat dalam menjaga dan memanfaatkan hasil hutan.
\end{abstract}

Kata Kunci: Forclime, Hutan, Partisipasi Masyarakat,

\section{Article Info}

Received

Accepted

Published

DOI

\author{
January 2021 \\ January 2021 \\ January 2021 \\ https://doi.org/10.30872/psd.v2i1.25
}

Copyright and License

Authors retain copyright and grant the journal right of first publication with the work simultaneously licensed under a Creative Commons Attribution 4.0 International License that allows others to share the work with an acknowledgment of the work's authorship and initial publication in this journal. 


\section{PENDAHULUAN}

Hutan Indonesia merupakan salah satu hutan tropis terluas ketiga di dunia dan ditempatkan pada urutan kedua dalam hal tingkat keanekaragaman hayatinya. Dari sisi ekologi, ekonomi dan sosial ternyata tingkat kerusakkan hutan di Indonesia masih relatif tinggi dari tahun ketahun diakibatkan adanya kegiatan eksploitasi yang tidak terkendali dan dilakukan secara masif tanpa memperhatikan aspek kelestarian serta keberlanjutan. Konsekuensinya, Indonesia menjadi emiter karbon terbesar ketiga di dunia akibat hilangnya hutan karena terjadinya alih fungsi lahan hutan, kebakaran hutan, serta penebangan liar yang tidak terkontrol. Pulau Kalimantan adalah salah satu paru-paru dunia karena luas hutannya yaitu, 40,8 juta hektar. Menurut data yang dikeluarkan departemen kehutanan angka deforestasi di Kalimantan pada tahun 2000 sampai 2005 mencapai sekitar 1,23 juta hektar. Artinya sekitar 673 hektar hutan di Kalimantan mengalami deforestasi setiap harinya pada periode tersebut. Sementara luas diseluruh Provinsi yang ada di Kalimantan mencapai 40,8 juta hektar.

Menurut Greenpeace, hutan Kalimantan hanya tersisa 25,5 juta di tahun 2010. Data yang di keluarkan oleh State of the World's Forest 2007 yang di keluarkan The UN Food dan Agriculture Organization (FAO), angka deforestasi Indonesia pada periode 2000-2005 adalah 1,8 juta hektar/tahun. Tingginya laju deforestasi hutan di Indonesia ini membuat Guiness Book of The Record menganugerahi Indonesia sebagai negara yang laju kerusakan hutannya tercepat di dunia. Sebuah prestasi yang tidak patut untuk dibanggakan. Deforestasi di Indonesia disebabkan oleh industri kayu yang semakin mempersempit hutan alami. Pengalihan fungsi (konversi) hutan untuk perkebunan kelapa sawit juga memberikan kontribusi besar terhadap semakin derasnya laju deforestasi. Konversi hutan menjadi area perkebunan kelapa sawit telah merusak lebih dari 7 juta hektar hutan pada tahun 1997. Berkurangnya luasan dan kualitas hutan di Kalimantan menjadi ancaman serius dari berbagai jenis satwa langka di Kalimantan antara lain, Orang Utan, Bekantan, Beruang Madu, dan berbagai Jenis Owa. Satwa langka itu kondisinya terjepit diantara menyempitnya hutan yang menjadi habitat mereka dan pemburuan liar.

Kabupaten Berau itu sendiri memiliki luas wilayah 2.194.299,525 Ha (RTRW Kab. Berau 2005-2011) terdiri dari Hutan Lindung 668.108,078 Ha, Hutan Produksi Terbatas 557.713,442 Ha, Hutan Produksi Tetap 179.299,747 Ha, Hutan Konservasi 156.448,289 dan Areal Penggunaan Lain (APL) 624.729,969 Ha. Tutupan Lahan sesuai hasil pemantauan Tim Program Menuju Indonesia Hijau (MIH) sampai dengan saat ini masih $\pm 80 \%$. Berdasarkan data Dinas Kehutanan Kabupaten Berau sampai dengan tahun 2010 luas alih fungsi hutan seluas $150.448 \mathrm{Ha}$ atau $6,85 \%$, masing-masing untuk keperluan pembangunan perkebunan = $60.224 \mathrm{Ha}$, pertambangan $=7.571 \mathrm{Ha}$, pertanian $=70.000 \mathrm{Ha}$, permukiman dan fasilitas pelayanan umum lainnya =.12.693 Ha. (Asmuransyah, 2016)

Forest and Climate Change Programme (FORCLIME) merupakan salah satu lembaga asing/NGO yang berasal dari Jerman yang menangani tentang pengelolaan hutan tradisional yang berkontribusi terhadap pengurangan emisi gas dan meningkatkan kehidupan pedesaan. Dengan adanya lembaga/NGO ini dapat mengurangi lajunya kerusakkan hutan di Indonesia lewat program pemberdayaan yang dapat meningkatkan partisipasi masyarakat pedesaandengan program-program pelestarian hutan tradisional milik masyarakat desa. Adapun program yang dijalankan oleh FORCLIME adalah dengan melakukan kegiatan Penanaman, Monitoring dan membuat Tapal Batas Desa antara desa yang lain dan Perusahaan dengan tujuan mengantisipasi terjadinya penebangan secara ilegal

\subsection{Fores and Climate Change Programme}

Forest And Climate Change Programme merupakan sebuah NGO berasal dari Jerman yang menangani tentang pengelolaan dan pemanfaatan hutan tradisional yang berkontribusi terhadap pengurangan emisi gas dan meningkatkan kehidupan masyarakat pedesaan. Melihat kondisi hutan yang semakin parah maka Kementrian Kehutanan bekerja sama dengan Forest And Climate Change Programme (FORCLIME) Jerman, di 3 (Tiga) Kabupaten di Kalimantan salah satunya di Kabupaten Berau. Program yang dilaksanakan bersama oleh Kementrian Kehutanan dan perhimpunan Jerman untuk kerja sama Internasional atau GIZ. Adapun kabupaten lain yang menjadi pilihan Forest And Climate Change Programme Kapuas Hulu (Kalbar), dan Malinau (Kaltara), Sejak Tahun 2009, pada fase pertamanya, Forest And Climate Change Programme (FORCLIME) membantu pemerintah serta pihak publik dan swasta dalam menciptakan kerangka, metode, jasa demi pengelolaan hutan lestari, konservasi alam, sampai pengenalan eko wisata.

Helmut Dotzauer, Strategic Area Maneger FORCLIME kepada National Geographic Indonesia menjelaskan, program bertujuan merancang pengelolaan hutan lestari yang berkontribusi terhadap pengurangan emisi gas rumah kaca dari sektor kehutanan dan meningkatkan kehidupan masyarakat miskin pedesaan.

Forest And Climate Change Programme mendukung pengelolaan hutan lestari di KPH Berau Barat. Dalam rangka membangun kapasitas pengelolaan hutan lestari melalui sertifikasi (FSC), FORCLIME bekerja sama dengan The Borneo Initiative (TBI) dan The Nature Conservancy (TNC). Salah satu bentuk dukungan 
FORCLIME terhadap kerja KPHP Berau Barat, Kalimantan Timur. Dukungan tersebut telah digagas sejak 2013 untuk dan mendapatkan sertifikasi pengelolaan hutan lestari melalui Forest Stewardship Council (FSC). FORCLIME melanjutkan kerja sama dan pengembangan kapasitas terkait dengan pengelolaan hutan lestari melalui sertifikasi hutan (SVLK/PHPL/FSC) di Kesatuan Pengelolaan Hutan (KPH) Berau Barat bersama dengan The Borneo Initiative (TBI) dan The Nature Conservancy (TNC). Tim gabungan ini melakukan kunjungan lapangan di tiga konsesi hutan yang berada dalam wilayah KPH Berau Barat pada tanggal 28 September hingga 7 Oktober 2016. Ketiga konsesi hutan yang dikunjungi adalah PT. Utama Damai Timber (UDIT), PT. Wana Bhakti Utama (WBPU) dan konsesi yang telah memiliki sertifikasi dari FSC, yaitu PT. Gunung Gajah Abadi (GGA). Kegiatan ini, yang merupakan bagian dari dukungan FORCLIME di bawah bidang strategis Pengelolaan Hutan Lestari (PHL), dilakukan di wilayah KPH Berau Barat, Kabupaten Berau, Kalimantan Timur. Dukungan FORCLIME kepada perusahaan konsesi hutan untuk mendapatkan sertifikat dengan skema mandatori SVLK/PHL dan Forest Stewardship Council (FSC) telah dilakukan sejak tahun 2013.

Pelaksanaan pengelolaan hutan lestari dan pembangunan KPH dilakukan secara intensif bersama dengan lembaga sertifikasi yang bertujuan untuk melibatkan masyarakat dan pihak swasta. Kegiatankegiatan yang dilakukan termasuk pelatihan teknis, kajian dampak sosial dan partisipasi masyarakat. Kegiatan-kegiatan tersebut, yang tujuannya untuk mendapatkan sertifikasi hutan, sedang dimonitor dan disupervisi oleh tenaga ahli bidang sertifikasi hutan. Pemberian sertifikasi hutan sangat tergantung dari perkembangan konsesi hutan dan pengalamannya dalam pengelolaan hutan lestari, proses untuk mendapatkan sertifikasi pengelolaan hutan lestari bervariasi pada masing-masing perusahaan. Beberapa faktor penentu adalah pengalaman dan investasi awal (misalnya hutan dan infrastruktur awal di hutan produksi alam), artinya ada perbedaan utama terkait dengan durasi operasionalisasi konsesi hutan; beberapa sudah beroperasi lebih dari 30 tahun, sementara konsesi lainnya baru mulai lima tahun yang lalu.

Dalam hal operasionalisasi hutan dan pembalakan rendah dampak untuk mengurangi emisi (Reduced Impact Logging to reduce emissions-RIL-C), ketiga konsesi tersebut telah menerima pelatihan penuh mengenai RIL. Hasil dari kegiatan ini adalah paling tidak terjadi pengurangan emisi 25\% pada wilayah seluas 136,000 ha, menurut metoda Verified Carbon Standard (VCS) yang dinyatakan oleh TNC.

Tim lapangan mengamati bahwa ketinggian air sungai memainkan peran penting dalam pengangkutan kayu, yang akhirnya berpengaruh terhadap pendapatan perusahaan. Banyak perusahaan konsesi bergantung pada kelayakan praktik pembuatan rakit log (rafting) berdasarkan kondisi sungai. Tingkat air sungai yang rendah menyebabkan lamanya periode penyimpanan kayu di sungai. Hal ini dapat menyebabkan penurunan kualitas log yang akhirnya mempengaruhi harga penjualan. Peristiwa alam lainnya, seperti curah hujan yang tidak teratur memiliki dampak besar terhadap kelancaran pengangkutan kayu, yang kemudian mempengaruhi keberlanjutan pembalakan di hutan alam produksi. Pengakutan kayu melalui jalan darat dapat menjadi pilihan untuk beberapa konsesi hutan, tetapi tidak untuk semua konsesi. Selain itu, medan yang menantang di daerah pegunungan dan pola curah hujan secara signifikan mempengaruhi kegiatan penebangan kayu. Hujan deras dapat menghentikan kegiatan penebangan, menunggu sampai cuaca cerah dan mengeringnya jalur angkut, sehingga dapat dilalui dengan aman oleh mesin dan truk pengangkut kayu tebangan.

\section{METODE}

Penelitian ini adalah penelitian evaluasi program partisipasi masyarakat dengan metode deskriptifinterpretatif. Data yang dihasilkan dari model penelitian ini adalah data deskripsi berupa kata-kata tertulis atau lisan dari orang-orang yang terlibat didalam praktik pemberdayaan. Penelitian ini mengevaluasi program-program partisipasi yang telah dilakukan oleh FORCLIME serta menjelaskan kendala-kendala yang dihadapi oleh NGO tersebut dalam melaksanakan programnya.

\section{HASIL DAN PEMBAHASAN}

Pada tahun 2007 ada pertemuan dari beberapa kepala-kepala negara di Bali pada saat itu yang menjadi topik pembahasan adalah Climate Change (Perubahan Iklim) pada saat itu Indonesia minta akan menurunkan emisi karbon sebanyak $26 \%$ dengan kekuatan sendiri apabila ada pihak asing yang ingin membantu dan bekerja sama maka Indonesia akan meningkatkan penurunan emisi karbon menjadi $42 \%$. Pada saat itu negara German menerima tawaran Indonesia dan ingin membantu bangsa Indonesia, akan tetapi dengan catatan ada aturan-aturan tertentu yang perlu di sepakati berupa perjanjian MOU antara Indonesia dan German. German menghibahkan dana melalui bank dunia KFW, kemudian KFW mencairkan dana dengan aturan-aturan tertentu dengan memastikan program tersebut berjalan sesuai dengan kesepakatan. Dana tersebut akan dicairkan melalui menteri keuangan Indonesia. Kemudian itu akan di rencanakan oleh BAPPENAS terkait program yang berkaitan dengan kehutanan dan lingkungan hidup, karena kedua lembaga ini yang di tunjuk sebagai pelaku di lapangan. Menteri kehutanan memilih daerah- daerah yang menjadi percontohan dengan nama Demonstration Activity (DA) yang artinya daerah atau areal percontohan. Adapun daerah-daerah 
kabupaten yang dipilih ialah, Kabupaten Kapuas Hulu di Kalimantan Barat, Kabupaten Berau di Kalimantan Timur, dan Kabupaten Malinau di Kalimantan Timur pada waktu itu dan sekarang menjadi Kalimantan Utara. Forest and Climate Change Programme terbagi menjadi dua yaitu, Teknical Coorperation dan Finantial Cooperation, adapun tugas dari keduanya ini adalah :

1. Teknical Cooperation adalah menghitung karbon dan menganalisa kondisi hutan.

2. Finantial Coorperation yang merupakan program yang bergerak dibidang kehidupan.

Kabupaten Berau memiliki tiga putaran, putaran pertama yaitu Demontration Activity (DA) 7, kemudian dijalankan di sepuluh Kampung dengan alasan bahwa kampung tersebut memiliki bekas HPH yang sudah mati atau sudah tidak beroperasi lagi. Daerah Berau adalah bekas HPH yang masih aktif atau masih beroperasi, adapun program-program Forest and Climate Change Programme yang dijalankan ditengahtengah perusahaan yang masih aktif tidak menjadi suatu masalah dengan kedua perusahaan tersebut, karena keduanya menjalankan program dengan tujuannya masing-masing. Forest and Climate Change Programme menjalankan programnya dikawasan KBNK/APL.

Daerah Desa Long Laai merupakan daerah pegunungan, dan hutan terjal, pada saat masyarakat Long Laai ingin menjaga atau melindungi hutan yang bukan kawasan KBK, FORCLIME sangat mendukung keinginan masyarakat karena kebanyakan masyarakat Long Laai masih tergantung dengan hasil hutannya sendiri, seperti berladang dan lain-lainnya. Kemudian FORCLIME mengelola bekas ladang tersebut mengajak masyarakat untuk menanam berbagai macam bibit tanaman seperti, Gaharu, Coklat, dan banyak jenis pohon kayu lain yang didominasi di daerah tersebut.

\subsection{Program-program Forest and Climate Change Programme}

Pada tahun 2012 Forest and Climate Change Programme mulai melakukan sosialisasi terkait program pemberdayaan yang akan dilaksanakan di Desa Long Laai. Pada waktu itu masyarakat Desa Long Laai menerima tawaran program-program pemberdayaan dari Forest and Climate Change Programme dengan tujuan mengurangi emisi gas karbon dan rumah kaca. Program-program tersebut akan dilaksanakan pada tahun 2013 dengan investasi jangka pendek yaitu melakukan pembibitan. Masyarakat minta bibit karet sebanyak 1.390 bibit. Kemudian pada tahun 2014 dilaksanakan investasi jangka panjang berupa bibit Meranti, Gaharu, dan Buah-buahan dengan jumlah keseluruhan 25.000 batang. Program ini sempat terhenti dikarenakan ada perubahan undang-undang nomor 23 yaitu gabungan kementrian lingkungan hidup dan kehutanan sehingga beberapa bibit yang sempat dibagikan kepada masyarakat banyak yang mati akibat musim panas. Pada tahun 2015 FORCLIME kembali melanjutkan program yang sempat terhenti dengan membuka lahan persemaian sebagai tempat masyarakat merawat bibit yang sebelumnya sudah di berikan. Kemudian Forest and Climate Change Programme memberikan bibit Gaharu dan Meranti lagi sebanyak 70.000 bibit dan dilaksanakan penanaman bibit dari tahun 2014 dan 2015. Kemudian dilanjutkan penanaman bibit tahun 2015 yang tidak sempat di tanam oleh masyarakat pada tahun 2016.

Pada tahun 2017 program pemberdayaan yang dilaksanakan adalah pemeliharaan tanaman yang sudah di tanam dari tahun sebelumnya, adapun kegiatan yang dilakukan oleh masyarakat adalah membersihkan lahan persemaian, dan pemupukan tanaman.

Program tahun 2018 masyarakat tidak lagi melakukan penanaman melainkan perawatan/pemeliharaan tanaman yang sudah di tanam di tahun sebelumnya yang menjadi tugas kami saat ini adalah memberikan suport kepada masyarakat agar tetap menjaga dan merawat tanaman yang sudah ditanam. Adapun tugas kami untuk mengetahui jalannya program ini adalah melakukan monitoring ke setiap lokasi penanaman.

1. Pembuatan Persemaian

Persemaian adalah proses persiapan yang dilakukan untuk memperoleh hasil dari rencana penanaman. Pembuatan persemaian tersebut di lakukan pada tahun 2015.

Adapun persiapan yang dilakukan oleh masyarakat dan pihak FORCLIME antara lain:
a) Persiapan Bibit
b) Persiapan lahan
c) Persiapan bahan/alat
d) Proses penanaman

Table 1. Persiapan Penanaman

\begin{tabular}{lllll}
\hline NO & Uraian kegiatan & Jenis & Luas & Jumlah \\
\hline 1 & Persiapan Bibit & karet & & 1.390 \\
2 & Persiapan lahan & & $\mathrm{L}=50 \mathrm{mtr}$ & \\
& & P=50 mtr & \\
3 & Persiapan bahan/alat & pupukk npk & $1000 \mathrm{~kg}$ & \\
& & herbisida & insektisida & 65 butir
\end{tabular}

Progress in Social Development: Volume 2 No 1 Januari 2021 


\section{Penanaman}

Penanaman pertama dilakukan sejak tahun 2015 dengan investasi bibit yang diberikan dari tahun sebelumnya. Penanaman tersebut dilakukan dengan dua tempat yaitu, di persemaian dan di lahan. Adapun hasil dari penanaman tersebut adalah sebagai berikut

Table 2. Hasil Penanaman

\begin{tabular}{|c|c|c|c|c|}
\hline No & Tahun & Berhasil & Tidak berhasil & Jumlah \\
\hline 1 & 2013 & 1.050 & 340 & 1.390 \\
\hline 2 & 2014 & 24.250 & 750 & 25.000 \\
\hline 3 & 2015 & 43.870 & 1.130 & 45.000 \\
\hline 4 & 2016 & 68.075 & 1.925 & 70.000 \\
\hline 5 & 2017 & & & \\
\hline \multirow[t]{2}{*}{6} & 2018 & & & \\
\hline & Jumlah bibit & 137.245 & 4.145 & 141.390 \\
\hline
\end{tabular}

\subsection{Partisipasi non fisik}

Partisipasi non fisik terlihat dari aktifnya masyarakat dalam memberikan pendapat/sumbangan pemikiran/saran dalam proses perencanaan dan pelaksanaan kegiatan. Partisipasi dapat diwujudkan pada berbagai macam kesempatan, seperti melalui pertemuan/rapat, melalui surat/saran dan tanggapan terhadap proses penanaman. Berikut ini dapat dijelaskan bagaimana partisipasi masyarakat dalam menyumbangkan ide/saran untuk menentukan penanaman yang dilaksanakan di Desa Long Laai.

Seperti yang kita ketahui bahwa masyarakat di Desa Long Laai merupakan masyarakat yang masih memiliki rasa solidaritas yang sangat tinggi dalam melaksanakan kegiatan yang berkaitan dengan kepentingan desa. Dalam hal ini masyarakat ikut berpartisipasi dalam menjalankan kegiatan program pemberdayaan yang ditawarkan oleh pihak Forest and Climate Change Programme dengan jumlah partisipasi kurang lebih $70 \%$ dari jumlah penduduk yang ada di Desa Long Laai

Table 3. Partisipan Non Fisik Masyarakat Desa Long Laai

\begin{tabular}{|c|c|c|c|c|}
\hline No & Nama & Jabatan & Ide/saran & Jenis Kelamin \\
\hline 1 & Jiu Nak Long & Ketua Adat & $\begin{array}{l}\text { Hutan Desa dapat } \\
\text { Dimanfaatkan } \\
\text { Untuk kegiatan } \\
\text { FORCLIME }\end{array}$ & Laki-laki \\
\hline 2 & marten & $\begin{array}{l}\text { Bendahara } \\
\text { FORCLIME }\end{array}$ & $\begin{array}{l}\text { Mendukung } \\
\text { Kegiatan } \\
\text { FORCLIME }\end{array}$ & Laki-Laki \\
\hline 3 & Martinus & $\begin{array}{l}\text { Ketua } \quad \text { Karang } \\
\text { Taruna }\end{array}$ & $\begin{array}{lr}\text { FORCLIME } \\
\text { Mebuat } \\
\text { Batas } & \text { Tapal } \\
\text { Hutan } & \text { Desa } \\
\text { Dengan } & \\
\text { Perusahaan } & \end{array}$ & Laki- Laki \\
\hline 4 & Helmi & TKK & $\begin{array}{l}\text { Bisa } \\
\text { Memberdayakan } \\
\text { kaum perempuan } \\
\text { dalam hal } \\
\text { pelaksanaan } \\
\text { program } \\
\text { FORCLIME }\end{array}$ & Laki- Laki \\
\hline 5 & Gun & Petani & $\begin{array}{l}\text { FORCLIME dapat } \\
\text { membantu } \\
\text { menyelesaikan } \\
\text { sangketa lahan } \\
\text { masyarakat } \\
\text { dengan perusahaan }\end{array}$ & Laki Laki \\
\hline
\end{tabular}


$6 \quad$ Nyuk Wing
Petani

Petani
FORCLIME dapat Laki Laki

membimbing

masyarakat agar

tetap menjaga

kelestarian Hutan

Mengajar

masyarakat

bagaimana

menanam dengan

baik

Berdasarkan keterlibatan yang disampaikan oleh pihak Forest and Climate Change Programme tidak terkecuali laki-laki dan perempuan semua masyarakat dapat menyampaikan ide/saran dalam menjalan kegiatan tersebut. Dalam upaya menggerakan program Forest and Climate Change Programme, dana merupakan salah satu penggerak utama yang menentukan keberhasilan penyelenggaraan program tersebut. Kenyataan di lapangan menunjukkan bahwa program Forest and Climate Change Programme tanpa di dorong kerjasama masyarakat dalam kegiatan pelaksanaan penanaman maka kegiatan tersebut tidak akan berjalan sesuai dengan yang diinginkan.

Masyarakat sadar akan pentingnya program penanaman, karena tanpa adanya swadaya dari masyarakat atau hanya mengandalkan bantuan-bantuan desa maka program tersebut tidak akan berjalan lancar. Adapun bibit tanaman yang akan mereka tanam adalah sebagai berikut :

1. Bibit Gaharu

Gaharu merupakan salah satu potensi yang masih ada di sekitar hutan masyarakat Desa Long Laai yang masih terjaga kelestariannya, dan menjadi salah satu mata pencarian masyarakat untuk memenuhi kebutuhan hidup mereka.

2. Bibit Karet

Masyarakat menanam bibit Karet sebagai memanfaatkan sejumlah kebun yang menjadi bekas ladang mereka dari tahun sebelumnya. Namun bibit karet ini tidak menjadi harapan masyarakat untuk memenuhi kebutuhan hidup mereka melainkan untuk mengisi tebangan hutan bekas ladang berpindah.

3. Bibit Meranti

Meranti merupakan salah satu kayu yang dapat dimanfaatkan oleh masyarakat sebagai bahan bangunan dan sebagai alat transportasi untuk memenuhi kebutuhan hidup. Dari beberapa saran diatas masyarakat sangat mengharapkan agar program Forest and Climate Change Programme dapat membantu masyarakat untuk tetap menjaga keutuhan hutan. Dalam program pemberdayaan Forest and Climate Change Programme membantu masyarakat untuk tetap antisipasi terjadinya Ilegal Logging dan penggundulan hutan.

\subsection{Partisipasi Fisik}

Kali ini masyarakat mulai berpartisipasi aktif dengan memberikan perawatan pada tanaman Gaharu, Karet dan Meranti yang sudah diberikan Forest and Climate Change Programme melalui pedampingan dan pelatihan. Forest and Climate Change Programme melakukan monitoring pada setiap kegiatan yang diberikan pada masyarakat. Kegiatan ini bertujuan mengecek keaktifan masyarakat.

Monitoring merupakan suatu pengawasan terhadap program pemberdayaan masyarakat yang di laksanakan oleh pihak Forest and Climate Change Programme dengan tujuan untuk mengetahui jalannya program dan memonitoring berbagai batas-batas antara hutan masyarakat dengan perusahaan. Adapun tujuan lain dari program ini dapat meningkatkan pengetahuan masyarakat yang melibatkan beberapa orang yang di ajak untuk memonitoring program tersebut. Adapun waktu yang di tentukan atau disepakati antara pihak Forest and Climate Change Program dengan masyarakat yaitu di jalankan 1 kali dalam 3 bulan atau triwulan.. Dalam memelihara hasil-hasil program pemberdayaan Forest and Climate Change Programme masyarakat dapat mencapai hasil yang cukup maksimal namun belum mencapai tujuan yang diinginkan karena banyak kendala yang harus dihadapi oleh masyarakat, seperti hama dan lain sebagainya

Table 4. Partisipan Fisik Masyarakat Desa Long Laai

\begin{tabular}{|c|c|c|c|c|}
\hline No & Nama & Jabatan & Sumbangan & Jenis Kelamin \\
\hline 1 & Jiu Nak Long & Ketua Adat & $\begin{array}{l}\text { Menyiapkan Lahan } \\
\text { Pembibitan }\end{array}$ & Laki-Laki \\
\hline 2 & Eng Dalah & Kepala Desa & $\begin{array}{l}\text { Menyiapkan Saran } \\
\text { Administrasi }\end{array}$ & Laki- Laki \\
\hline
\end{tabular}




\begin{tabular}{|c|c|c|c|c|}
\hline & & & Jalannya Program & \\
\hline 3 & Sabinus Binoi & Petani & $\begin{array}{l}\text { Ikut Dalam } \\
\text { Pengawasan }\end{array}$ & Laki laki \\
\hline 4 & Helmi & TKK & $\begin{array}{l}\text { Ikut Terlibat dalam } \\
\text { Menyelesaikan } \\
\text { Administrasi } \\
\text { Program }\end{array}$ & Laki- Laki \\
\hline 5 & Marten Gun & Petani & $\begin{array}{l}\text { Ikut dalam } \\
\text { Kegiatan } \\
\text { monitoring }\end{array}$ & Laki-LAki \\
\hline 6 & MArten & $\begin{array}{l}\text { Bendahara } \\
\text { FORCLIME }\end{array}$ & $\begin{array}{l}\text { Menyiapkan } \\
\text { Transportasi dalam } \\
\text { kegiatan } \\
\text { monitoring }\end{array}$ & Laki-laki \\
\hline 7 & Agustina & Petani & Ikut menanam bibit & Perempuan \\
\hline
\end{tabular}

Pemeliharaan merupakan suatu kegiatan yang sangat penting untuk mendapatkan hasil yang lebih baik. Adapun cara pemeliharaan masyarakat Desa Long Laai tidak semuanya memelihara tanaman yang di berikan oleh pihak Forest and Climate Change Programme dengan baik di karenakan masyarakat tidak memiliki pekerjaan yang tetap dan dekat di sekitar Desa, akan tetapi lebih banyak masyarakat memiliki tanaman yang terawat. Tujuan dari program ini adalah untuk menjaga kelestarian hutan agar terhindar dari bencana alam dan penggundulan hutan. Forest and Climate Change Programme mengajak masyarakat untuk menanam bekas ladang berpindah dan bekas HPH. Adapun tujuan dari monitoring adalah untuk melakukan pemantauan terhadap penggarapan hutan secara ilegal dan penangkapan satwa-satwa yang di lindungi dari perusahaan yang ada disekitar Desa Long Laai.

\subsection{Faktor-faktor Pendukung dan Penghambat Partisipasi Masyarakat}

1.Faktor pendukung terjadinya partisipasi masyarakat

a) Sumber Daya Alam

Sumber Daya Alam merupakan segala sesuatu yang berasal dari alam yang dapat dimanfaatkan untuk memenuhi kebutuhan hidup. Maka dari itu Desa Long Laai memiliki kawasan hutan terjal dengan memiliki berbagai jenis tumbuhan, satwa-satwa, dan Sumber Daya Alam lainnya yang masih tetap terjaga keutuhannya.

b) Masyarakat Homogen

Masyarakat homogen adalah masyarakat dengan identitas ras, etnis, agama dan budaya yang sama serta cenderung mengikuti gaya hidup dengan budaya yang sama. Masyarakat Desa Long Laai cenderung mengikuti gaya hidup yang dapat meningkatkan kehidupan yang lebih baik.

c) Iklim/Cuaca

Iklim merupakan sesuatu yang sangat berpengaruh dalam hal menanam untuk mendapat hasil yang lebih baik bagi para petani. Desa Long Laai memiliki iklim yang cukup baik dalam menanam bibit apapun yang dapat menghasilkan dan dapat memenuhi kebutuhan hidup.

Faktor-faktor ini merupakan pendukung masyarakat dan Forest and Climate Change Programme untuk melakukan penanaman agar mendapatkan hasil yang lebih baik. Dalam hal ini faktor pendukung terjadinya partisipasi masyarakat seperti Sumber Daya Alam, Masyarakat Homogen dan Iklim Cuaca sangat menenuntukan tingkat partisipasi masyarakat dalam melakukan pelestarian alam (penghijauan).

2.Faktor Penghambat partisipasi masyarakat

Dalam pelaksanaan program Forest and Climate Change Programme tentu tidak berjalan sesuai rencana yang telah dikonsepkan, ada beberapa hal yang menjadi penghambat pelaksanaan kegiatan Forest and Climate Change Programme salah satunya adalah sistem lahan berpindah, masyarakat adat Dayak Ga'ai merupakan masyarakat pedalaman kalimantan yang sistem kehidupannya masih sangat bergantung dengan alam, oleh sebab itu dalam pelaksanaan kegiatan pertanian suku dayak memanfaatkan hutan rimba yang paling cocok untuk ladang berpindah, tetapi dalam hal ini masyarakat dayak tidak melakukan perpindahan sesuka hati mereka dan ada aturan-aturan yang telah ditentukan oleh adat agar kondisi alam tetap terjaga. Hal 
inilah yang menjadi penghambat untuk pelaksanaan program Forest and Climate Change Programme, karena menjadi sulit bagi lembaga tersebut untuk menentukan lahan yang akan dikelola.

\section{KESIMPULAN}

Ditulis dalam 1 paragraf. Berisi uraian tentang kesimpulan dan saran yang menjawab pertanyaan dan Berdasarkan hasil penelitian dan pembahasan penulis menarik kesimpulan dari masalah sebagai berikut:

1. Ada dua strategi Forest and Climate Change Programme dalam melaksanakan program pemberdayaan masyarakat di Desa Long Laai. Strategi pertama adalah pengelolaan hutan berkelanjutan untuk meningkatkan kondisi kehidupan masyarakat pedesaan yang rentan terhadap perubahan iklim. Strategi kedua adalah dengan pendekatan Forest and Climate Change Programme. Program ini menawarkan beberapa program pemberdayaan dengan cara mensosialisasikan langsung kemasyarakat lewat pertemuan yang sudah dijadwalkan oleh pihak Forest and Climate Change Programme.

2. Di satu sisi, program ini berhasil meningkatkan kesadaran masyarakat akan kerusakan hutan, kegiatan kegiatan penjagaan keutuhan hutan dan peningkatan pengetahuan mereka tentang hidup berdampingan dengan hutan.

3. Ada dua faktor pendukung jalannya program ini adalah SDA, berupa kawasan hutan terjal yang masih terjaga kelestariannya, dan masyarakat Homogen, masyarakat yang cenderung untuk mengikuti keinginan dan tujuan yang sama terhadap pelestarian hutan.

4. Namun di sisi lain, program ini memiliki kekurangan di dalam penyediaan fasilitator pendamping program pemberdayaan masyarakat.

5. Faktor penghambat program ini adalah budaya ladang berpindah dan klaim tanah yang telah ditinggalkan, menyulitkan pihak FORCLIME dalam mendapatkan lahan untuk persemaian bibit..

\section{DAFTAR PUSTAKA}

Achmaliadi, Restu. et.al. 2001. Keadaan Hutan Indonesia. Bogor

Huda, Miftachul. 2009. Pekerjaan Sosial dan Kesejahteraan Sosial: Sebuah pengantar. Yogyakarta,

Jones, Charles O. 1996. Pengantar Kebijakan Publik (Public Policy). Jakarta: PT Raja Grafindo Persada

Kristanto, 2013. Ekologi Industri. Yogyakarta: Andi offset.

Koentjaraningrat. 2012, Pengantar Ilmu Antropologi 1. Jakarta: PT Rineka Cipta

Mardikanto, Totok. \& Soebiato, Poerwoko. 2015. Pemberdayaan Masyarakat Dalam Perspektif Kebijakan Publik. Bandung: Alfabeta

Payne, S. 1997. Social Work and Community Care. London: Mc. Millan.

Rachman, Effendi, et.al. 2007. “Kajian pola-pola pemberdayaan masyarakat sekitar hutan produksi dalam mencegah illegal logging”. Jurnal Penelitian Sosial dan Ekonomi Kehutanan Vol.4No.4 Desember2007.

Suhendra. 2006, Peranan Birokrasi dalam Pemberdayaan Masyarakat. Alfabeta: Bandung.

Soekanto, Soejono. 1990. Sosiologi Suatu Pengantar.Jakarta: PT Raja Grafindo Persada.

Suharto, Edi. 2009. Membangun Masyarakat, Memberdayakan Rakyat: Bandung, PT. Rafika Aditama.

Sardjono, M.A.1998. Upaya Pemberdayaan Masyarakat diSekitar Kawasan Hutan di Kaltim. 